\title{
Pembuatan Prototype Sistem Kompressor Udara Start Pada Kapal
}

\author{
Ma'ruf Nur Aziz $^{1 *}$, Amad Narto ${ }^{2}$, Mohammad Sapta Heriyawan ${ }^{3}$ \\ ${ }^{1,2,3}$ Politeknik Ilmu Pelayaran Semarang,Jl. Singosari Raya No.2A, Wonodri, Kec. \\ Semarang Sel., Kota Semarang, Jawa Tengah 50242 \\ * Corresponding Author. E-mail : marufnuraziz@gmail.com. Telp : 082326271011
}

\begin{abstract}
Abstrak
Pada era ini banyak metode pembelajaran yang digunakan dalam dunia pendidikan instansi pelayaran yang ada, salahsatunya adalah metode pembelajaran dengan menggunakan model alat peraga permesinan yang ada di kapal. Sehingga penulis mengambil subjek penelitian membuat sebuah alat peraga salah satu permesinan di atas kapal yaitu pembuatan prototype sistem kompresor udara start pada kapal. Tujuan penelitian ini adalah untuk mendeskripsikan proses pembuatan, sistem kerja, serta manfaat dari prototype sistem kompresor udara start pada kapal. Metode yang digunakan yaitu Research and Development, merupakan prosescuntuk mengembangkan suatu produk baru atau menyempurnakan produk yang sudah ada, baik itu perangkat keras maupun perangkat lunak. Pembuatan prototype sistem kompresor udara start pada kapal ini memanfaatkan dua buah modul elektronika dimana modul tersebut adalah modul jenis timmer delay relayl channel, dan modul timmer delay relay 2 channel dimana kedua modul tersebut diprogram langsung dengan tombol yang ada pada modul. Sistem kerja yang ada pada alat peraga ini adalah kompresor mengisi udara pada tabung hingga tekanan mencukupi, kemudia udara bertekanan pada tabung akan digunakan untuk start mesin induk yang berupa simulasi sebuah silinder piston dari mesin 4 tak. Sistem ini dapat berjalan karena adanya kontrol otomatisasi dari modul elektronika.
\end{abstract}

Kata Kunci: Protoype, Kompresor, Timmer Delay Relay.

\begin{abstract}
In this era, there are lot of learning methods in maritime education especially on board. One of the method using machinery simulation on board. So the author decided took the subject to make a prototype one of the machinery on board, it's air compressor system start on the ship. The purpose of this research to know how it work and the system, as well as the benefits of this air compressor simulation system start on board. The method used is Research and Development, it's used to develop a new product or improve an existing product included hardware or software. This starting air compressor simulation system on board is utilized by two electronic modules where the module type is timmer delay relayl channel module, and a 2-channel timmer delay relay module. Both of the modules are programmed directly with the buttons on the module. The compressor system by filling the air on the tube until the pressure is sufficient, then the compressed air on the tube will be used to start the main engine in the form of a simulation of a piston cylinder of a 4 stroke engine. This system can run due to automation control of electronic modules.
\end{abstract}


Keyword : Prototype, compressor, timmer delay relay

\section{PENDAHULUAN}

Pada era modern seperti saat ini ekonomi perdagangan kian meningkat pesat, sehingga pendistribusian barang barang dalam lingkup nasional atau internasional memerlukan transportasi yang cukup baik dalam transportasi darat, laut, maupun udara. Dalam hal ini transportasi laut adalah moda transportasi yang paling banyak digunakan dalam pengiriman barang, sumberdaya, maupun transportasi bagi penumpang baik lintas nasional ataupun internasional. Sehingga banyak instansi sekolah pelayaran yang terus muncul di Indonesia. Persaingan tiap sekolah pelayaran pun kian ketat untuk mencetak lulusan perwira pelayaran yang handal dan kompeten.

Maka dari itu, pembelajaran tentang permesinan di atas kapal sangat penting untuk dikuasai oleh peserta didik sebelum nantinya terjun ke dunia kerja di perhubungan transportasi laut. Banyak metode pembelajaran yang digunakan dalam dunia pendidikan instansi pelayaran yang ada, salahsatunya adalah metode pembelajaran dengan menggunakan model alat peraga permesinan yang ada dikapal. Dengan melihat peragaan dari suatu permesinan diatas kapal melalui alat peraga rancang bangun, pemahaman dan wawasan tentang sistem kerja dan komponen komponen dari permesinan itu dapat mudah dipahami.

Selain alasan penulis mengambil penelitian dan pembuatan alat rancang bangun sebagai media pembelajaran, penulis juga mengaplikasikan modernisasi kemajuan teknologi di era milenial. Di era modern banyak peralatan peralatan canggih serta sumber-sumber ilmu yang dapat dimanfaatkan sebagai acuan untuk pembuatan rancang bangun alat peraga.

Sebagai pengaplikasian dari pemahaman dan pembelajaran selama taruna melaksanakan praktek laut tentang macam macam permesinan di atas kapal beserta sistem kerjanya, penulis membuat penelitian alat peraga salah satu permesinan bantu yang umum ada di atas kapal yaitu main air compressor. Permesinan bantu tersebut dipilih karena main air compressor merupakan permesinan bantu penghasil udara bertekanan yang dapat digunakan sebagai udara start mesin induk di atas kapan. Selain untuk udara start mesin induk, udara bertekanan dari kompresor yang ditampung pada tabung udara atau air reservoir juga dapat digunakan untuk quick closing valve, suling kapal, dan membersihkan permesinan di kamar mesin.

Untuk mempermudah pembaca untuk memahami tentang main air compressor, penulis membuat karya ilmiah tulis skripsi dengan mencermati latar belakang dan judul penulis merumuskan rumasan masalah sebagai berikut: Mendeskripsikan prosedur cara membuat prototype sistem kompresor udara start pada kapal. Mendeskripsikan sistem kerja dari prototype sistem kompresor udara start pada kapal. Menyimpulkan manfaat dari pembuatan prototype sistem kompresor udara start pada kapal. 


\section{KAJIAN LITERATUR}

Pengertian perancangan menurut Satzinger, Jackson, Burd (2010: 4) perancangan sistem adalah proses menentukan secara detail bagaimana komponen-komponen sistem informasi secara fisik dapat diimplementasikan dan memenuhi persyaratan pengguna sistem.

Menurut O’Brien (2010) perancangan sistem adalah proses merancang sistem dari model yang ada dan dimodifikasi sampai mempresentasikan apa yang dapat dilakukan oleh sistem baru. Berdasarkan pengertian mengenai perancangan yang telah dipaparkan di atas, maka dapat diperoleh kesimpulan bahwa perancangan sistem adalah proses kegiatan mendesain sesuatu model untuk menghasilkan karya yang bermanfaat bagi pemakai sistem tersebut dan dapat mencapai hasil yang memuaskan bagi pemakai sistem dari model yang dirancang.

Menurut Tahara \& Sularso (2006) kompresor adalah mesin untuk memampatkan udara atau gas. Kompresor udara biasanya menghisa udara dari atmosfer. Namun ada pula yang menghisap udara atau gas yang bertekanan lebih tinggi dari tekanan atmosfer. Dalam hal ini kompresor bekerja sebagai penguat atau booster. Sebaliknya adapula kompresor yang enghisap udara atau gas yang bertekanan lebih rendah dari atmosfer, dalam hal ini kompresor sebagai pompa vakum.

Arsyad (2013) mengatakan, Alat peraga adalah media alat bantu pembelajaran dengan segala macam benda yang digunakan untuk memperagakan materi pelajaran. Menurut Annisah (2017) alat peraga adalah satu diantara beberapa cara untuk mengaktifkan siswa berinteraksi dengan materi ajar diperlukan suatu alat bantu yang disebut alat peraga. Dalam interaksi ini siswa akan membentuk komunitas yang memungkinkan mereka mencintai proses pembelajaran. Pemanfaatan alat peraga dalam pembelajaran matematika sangat diperlukan karena dengan menggunakan alat peraga siswa berpikir abstrak sehingga penggunaan alat peraga sangat diperlukan dalam menjelaskan dan menanamkan konsep pembelajaran matematika.

Dan penulis mengambil kesimpulan alat peraga adalah alat bantu pembelajaran yang berupa segala macam benda yang digunakan untuk memperagakan materi pembelajaran dan memiliki konsep sama dengan materi pembelajaran yang dipelajari, serta memiliki ciri-ciri dari konsep yang dipelajari. Alat peraga memiliki fungsi utama yaitu untuk mempermudah dan memperjelas materi pembelajaran terutama permesinan diatas kapal agar nantinya dapat bermanfaat bagi pembaca. Untuk mempermudah memahami jalanya penelitian, maka penulis membuat kerangka pikir penelitian sebagai berikut : 


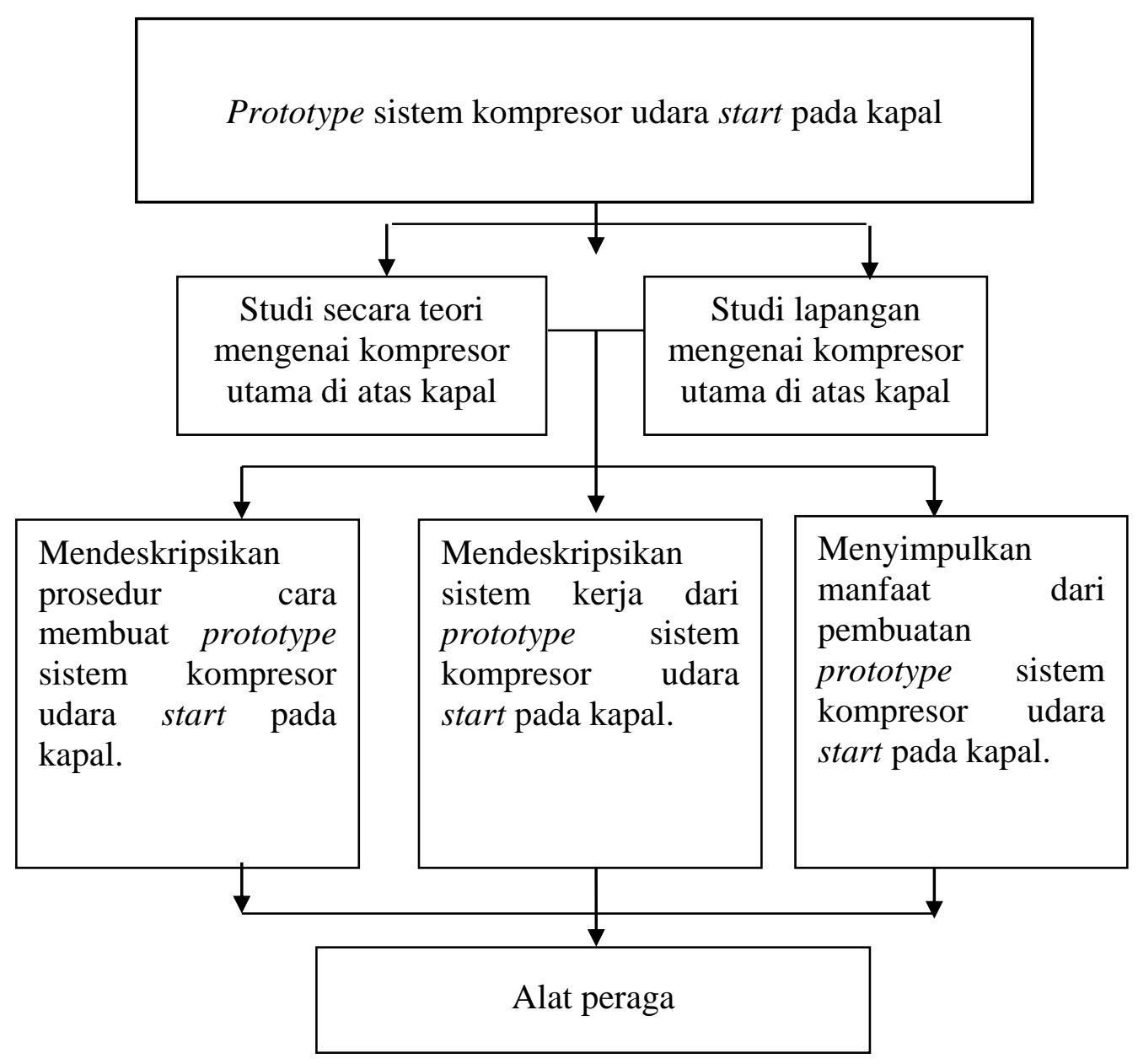

Gambar 1. Kerangka Pikir

\section{METODE PENELITIAN}

Dalam perancangan ini metode yang digunakan adalah Research and Development (penelitian dan pengembangan) (Astriawati, 2020) yang memiliki tujuan untuk menghasilkan sebuah produk melalui proses desain penelitian serta pengembangan dari penelitian dengan referensi dari buku pedoman dan rancang bangun model alat peraga permesinan sederhana sebagai alat praktikum dan pembelajaran.

Alat peraga praktikum ini diharapkan dapat menjadi alat praktikum pembelajaran yang dapat membantu mengatasi kesulitan dalam praktikum dan mempermudah pembelajaran khususnya taruna dan peserta diklat saat melakukan praktek. Pengembangan yang penulis adaptasi dalam penelitian ini adalah mengadaptasi dari teori menurut Borg dan Gall ( 2015) menyatakan bahwa dimungkinkan untuk membatasi penelitian dalam skala kecil termasuk membatasi langkah penelitian. Penerapan langkah - langkah pengembangan disesuaikan dengan kebutuhan peneliti.

Dalam metode penulisan dan pembuatan alat peraga rancang bangun tidak terlepas dari metode pengembangan yang digunakan penulis dalam membuat 
karya tulis. Terdapat metode yang dapat digunakan, namun dalam hal ini penulis menggunakan metode yang sudah umum digunakan dalam perancangan suatu model alat peraga. Metode pengembangan yang penulis gunakan adalah model ODDIE atau biasa diartikan sebagai Observasi, Design, Development or Production, Implementation, and Evaluation.

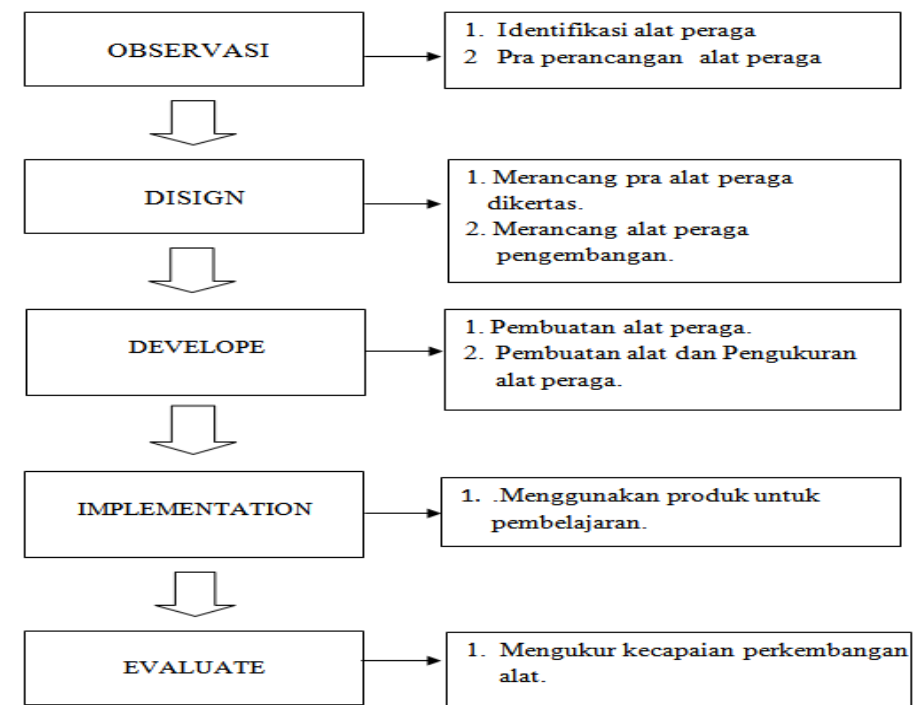

Gambar 2. Diagram metode model ODDIE

\section{A. Prosedur Penelitian}

Prosedur penelitian merupakan langkah-langkah yang dilakukan peneliti secara teratur untuk mencapai tujuan penelitian, (Fitrah, 2018).

\section{Tahap Observasi}

Menurut Timotius (2017) observasi adalah cara mengamati dan mempelajari suatu hal untuk tujuan tertentu, misalnya adalah untuk mengembangkan suatu alat produk tertentu. Jadi umumnya tahap ini adalah tahap awal yang digunakan peneliti.

2. Desain Perancangan Alat

Desain perancangan yang peneliti rancang adalah dengan pembuatan rancangan dimana peneliti memperhitungkan ukuran serta komponen komponen rangkaian elektronik yang digunakan peneliti dalam membuat model rancang bangun.

3. Tahap Perancangan Alat

Setelah proses pembuatan bagian bagian dari model rancang bangun main air compressor, proses tahapan selanjutnya adalah tahap perancangan. Perancangan yang penulis buat dibagi menjadi dua bagian, karena terdapat juga bgaian bagian umum dari model, dan bagian bagian dari komponen elektronikanya.

4. Tahap Pembuatan Alat

Pembuatan dari bagian bagian yang ada pada model rancang bangun yang penulis buat ini dibuat berdasarkan sketsa dan desain yang penulis buat pada langkah sebelumnya. Hal ini dikarenakandalam penelitian dan perancangan ini 
penulis membuat alat peraga rancang bangun main air compressor yang penulis buat sendiri.

\section{Tahap Pengukuran Desain}

Rancang bangun model alat peraga yang telah selesai dibuat dan dibangun belum bisa diketahui berfungsi dengan baik atau tidak maka dalam tahap ini penulis melakukan pengetesan dari komponen elektroniknya apak ketika dihubungkan dengan sumber listrik dapat bekerja dengan benar atau tidak.

\section{Tahap Pengujian Alat}

Setelah alat selesai dibuat dan sumber penggerak dapat berfungsi dengan baik, langkah berikutnya adalah tahap pengujian alat. Pengujian dilakukan mulai dari komponen elektronik yang berfungsi dengan baik, kompresor yang dapat menghasilkan udara bertekanan, serta sistim penghubung antara kompresor, botol angin, serta mesin induknya, agar tidak terjadi kebocoran pada selang udara.

7. Tahap Evaluasi

Tahapan evaluasi ini adalah tahapan kesimpulan dimana setelah penulis melakukan tahapan pengujian alat peraga rancang bangun model main air compressor, penulis dapat menyimpulkan hasil dari pengujian alat peraga tersebut.

\section{B. Sumber dan Subjek Penelitian}

Diatas kapal terdiri dari permesinan induk dan permesinan bantu yang terdiri dari beberapa pesawat permesinan yang memiliki fungsi dan cara kerja masing masing namun berhubungan dengan satu sama lain menjadi sebuah sistem. Dengan demikian, rancang bangun merupakan kegiatan menerjemahkan hasil analisa ke dalam bentuk prototipe model rancang bangun yang kemudian menciptakan/memperbaiki sistem yang sudah ada.

\section{Teknik Pengumpulan Data}

Tahapan dimana peneliti mendapatkan data yang diperlukan untuk penelitian. Pengumpulan data dilakukan untuk memperoleh informasi yang dibutuhkan untuk mendukung tercapainya penelitian (Saifuddin \& Wekke, 2018). Pengumpulan data merupakan proses dimana penulis memperoleh data-data, bahan, kenyataan-kenyataan, keterangan, serta informasi yang terpercaya, dimana hal tersebut sangat diperlukan sebagai acuan dasar penulis untuk menciptakan alat peraga. Tahapan untuk mendapatkan data yang diinginkan dalam proses penelitian dan perancangan pengembangan ini menggunakan observasi, kepustakaan, wawancara, dan dokumentasi. Observasi yaitu dimana pada tahap ini objek yang diobservasi adalah kompresor utama dan sistem udara start mesin induk pada kapal ketika peneliti melaksanakan praktek laut di atas kapal Kepustakaan, dimana tema kepustakaan yang dibutuhkan adalah tentang kompresor, elektronika dasar, dan tentang modul timmer delay relay, dan kepustakaan buku - buku tentang metode perancngan dan pengembangan. Berikutnya adalah wawancara, wawancara yang dilakukan peneliti adalah wawancara dengan dosen pembimbing dan pengajar di instansi terkait permesinan bantu. Menurut Prasetyo, 2018) wawancara adalah percakapan yang dilakukan dua pihak yaitu pewawancara mengajukan pertanyaan dan yang di wawancarai memberikan jawaban atas pertanyaan. Dokumentasi, dimana penelitian ini mengambil dokumentasi proses demi proses pembuatan hingga alat siap diuji. 


\section{Alat dan Bahan}

Untuk mempermudah proses pembuatan maka peneliti harus menentukan alat dan bahan. Daftar alat bantu yang dipergunakan dalam pembuatan prototype sistem kompresor udara start kapal yang dibuat penulis adalah:

Tabel 1. Daftar nama alat

\begin{tabular}{lll}
\hline \multicolumn{1}{c}{ Nama Alat } & Jumlah & \multicolumn{1}{c}{ Fungsi } \\
\hline Gergaji besi & 1 unit & Untuk memotong kayu dan paralon \\
Mesin bor & 1 unit & $\begin{array}{l}\text { Untuk melubangi akrilik dan kayu } \\
\text { landasan }\end{array}$ \\
Mesin bubut kayu & $1 \mathrm{unit}$ & Untuk memotong dan menghalskan bahan \\
Obeng & $1 \mathrm{unit}$ & Untuk mengikat sekrup \\
Spidol & $1 \mathrm{unit}$ & Untuk menandai bahan yang dikerjakan \\
Mata gerinda mini & $1 \mathrm{set}$ & Untuk memotong dan merapikan bahan \\
Pisau/Cutter & $1 \mathrm{unit}$ & Untuk merapikan dan memotong bahan \\
Tang & $1 \mathrm{unit}$ & Untuk mengikat baut ukuran tertentu \\
Amplas & $1 \mathrm{set}$ & Untuk menghaluskan bahan \\
Penggaris & $1 \mathrm{set}$ & Untuk menggaris akrilik dan mendesain \\
Pensil & $1 \mathrm{unit}$ & Untuk membuat sketsa \\
Lem paralon & $1 \mathrm{unit}$ & Untuk merekatkan paralon \\
Lem G & $2 \mathrm{unit}$ & Untuk memperkuat lem paralon \\
\hline
\end{tabular}

Tabel 2. Daftar nama bahan

\begin{tabular}{|c|c|c|}
\hline Nama Bahan & Jumlah & Keterangan \\
\hline Mini kompressor & 1 unit & 12v 10 ampere \\
\hline Papan kayu & 1 lembar & $50 \times 50 \mathrm{~cm}$ \\
\hline Selang 5/16 & $3 \mathrm{~m}$ & $3 m$ ukuran $5 / 16$ \\
\hline Pipa pvc 4, & 1 unit & $\mathrm{D} 4$ ', panjang $1 \mathrm{~m}$ \\
\hline Prop pipa $4 "$ & 2 unit & D 4"' untuk menutup pipa \\
\hline Mur & 3 unit & $\mathrm{D} 4{ }^{\prime}$, \\
\hline Klem selang & 22 unit & Untuk selang 5/16 \\
\hline Neppel selang & 20 unit & Drat 4', untuk selang 5/16 \\
\hline Selenoid valve & 1 unit & $12 \mathrm{v}$, drat $4 "$ \\
\hline Relief valve & 1 unit & $120 \mathrm{psi}$ \\
\hline Pressure gauge & 2 unit & Max 1 bar \\
\hline Silinder plastik & 1 unit & Diameter $8 \mathrm{~cm}$ \\
\hline Push button & 2 unit & push button on/off \\
\hline timmer relay & 2 unit & 3 display 4 button, dengan relay \\
\hline Dinamo & 1 unit & 12 v 5 ampere \\
\hline Elbow & 7 unit & Ukuran 5/16 \\
\hline Valve $5 / 16$ & 1 unit & Ball valve \\
\hline Nepple ban sepeda & 1 unit & Bekas ban dalam \\
\hline Karet ban dalam & 1 unit & Bekas ban dalam \\
\hline Power suplay & 1 unit & $210-240 \mathrm{v}$ ac to $12 \mathrm{v}$ de $10 \mathrm{~A}$ \\
\hline
\end{tabular}




\section{E. Waktu Dan Tempat Perancangan}

\section{Waktu Perancangan}

Waktu yang ditetapkan oleh penulis untuk melakukan penulisan dan laporan dari rancang bangun ini dilakukan pada tanggal 28 Agustus 2020 hingga Januari 2021. Hasil pengalaman dan ilmu pengetahuan yang telah dipadukan dari permasalahan lapangan yang dialami serta fakta-fakta yang ditemukan dan dialami penulis dalam merancang rancang bangun alat peraga main air compressor

2. Tempat Penelitian

Tempat dilaksanakan penelitian ini mulai dari persiapan, desain, pembuatan, perancangan mekanik, perancangan dan pengujian alat dilakukan dan dikerjakan di workshop Pip Semarang. Workshop tersebut berlokasi di jalan singosari raya No. 2A kota Semarang, Jawa Tengah 50242.

\section{PEMBAHASAN}

Salah satu tugas pokok lembaga pendidikan (dalam ini kampus/ Politeknik Ilmu Pelayaran (PIP) Semarang) adalah menyiapkan Mahasiswa yang dimaksud adalah Taruna agar dapat mencapai perkembanganya secara optimal. (Prasetyo, 2018). Politeknik Ilmu Pelayaran Semarang (PIP Semarang) adalah perguruan tinggi bidang pelayaran dan kepelabuhanan yang bertempatan di kota Semarang Jawa Tengah, Indonesia. PIP Semarang merupakan lembaga yang berada dibawah Kementerian Perhubungan Republik Indonesia dimana di lembaga inilah protoype sistem kompresor udara start pada kapal ini dibuat tepatnya Di workshop PIP Semarang.

\section{A. Hasil Penelitian}

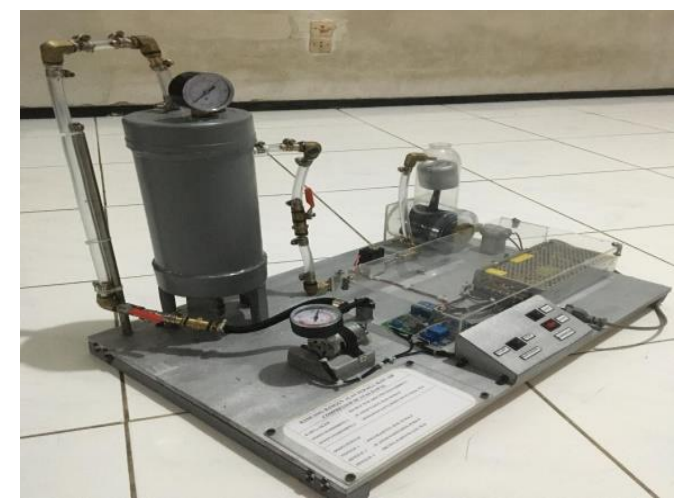

Gambar 3. Prototype sistem kompresor udara start pada kapal

Hasil penelitian rancang bangun ini menghasilkan sebuah alat peraga atau prototype sistem kompresor udara start pada kapal. Peneliti melakukan pengujian pada tiap-tiap komponen yang ada pada prototype sistem kompresorudara start pada kapal ini dengan mengamati berapa tekanan yang dihasilkan serta modul komponen elektronik yang ada didalamnya. Fungsi dari pengujian tersebut adalah untuk mengetahui cara kerja dari sistem kompresor udara start pada kapal yang dibuat oleh peneliti, yang nantiya alat peraga ini akan digunakan untuk media 
pembelajaran sesuai dengan harapan dari peneliti membuat alat peraga atau prototype alat peraga ini.

\section{B. Proses Pembuatan}

\section{Menyiapkan Alat dan Bahan}

Dalam melakukan proses pembuatan suatu karya pasti tahap yang harus dilakukan pertama adalah menyiapkan alat dan bahan agar sesuai dengan tujuan laporan dan proses pembuatan lebih memiliki efisiensi dalam hal waktu. Persiapan alat dan bahan harus dilakukan dengan baik karena kelancaran dalam pembuatan alat peraga ini dipengaruhi oleh persiapan yang matang. Peneliti melakukan pendataan dan riset guna mengumpulkan informasi jenis alat dan bahan yang baik untuk digunakan dalam proses pembuatan alat peraga ini.

2. Membuat Desain

Tahap selanjutnya dari pembuatan alat peraga ini adalah tahap desain sistem udara start dari main air compressor dengan menggunakan sketsa gambar sistem kemudian digambar kembali menggunakan komputer.

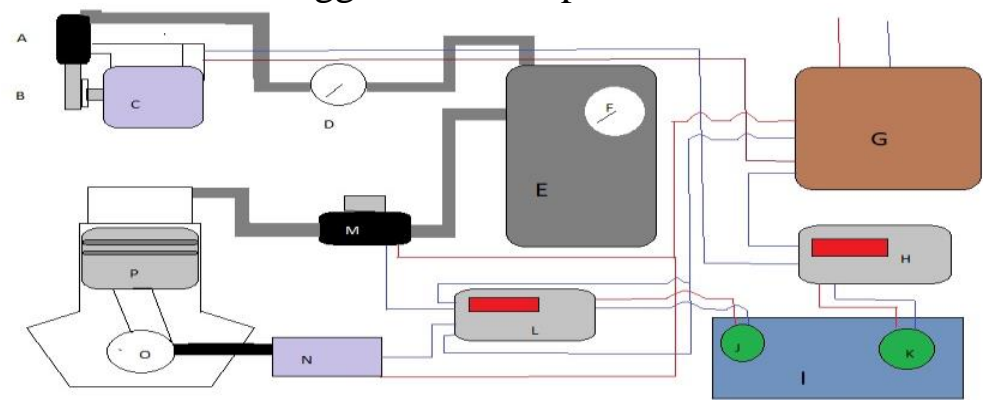

Gambar 4. Bagan sistem prototype kompresor udara start

\section{Menentukan bahan}

Dalam proses pembuatan rancang bangun alat peraga main air compressor ini, penulis menggunakan kayu jenis kayu Sengon yang umumnya banyak ditemui, dan bahan kayu ini digunakan sebagai bahan pondasi dari alat peraga ini. Penulis memiliki banyak pertimbangan untuk memilih dan menentukan bahanbahan yang akan digunakan oleh penulis untuk merancang alat peraga tersebut. Dan penulis pun menyimpulkan bahan bahan yang digunakan meliputi kayu, pipa paralon, papan triplek, mika transparan selang angin 5/16"

4. Pembuatan Bagian dari Alat Peraga

Pondasi alat peraga ini terbuat dari kayu Sengon, kayu jenis ini memiliki keunggulan yaitu mudah didapat, serta ringan namun tettap bisa digunakan sebagai pondasi dari suatu alat. Kayu sengon yang digunakan yaitu kayu dengan ukuran 60 x 40 x 1,5 cm dimana kayu setelah dipotong disatukan dengan ukuran, kemudian permukaan dan tepi dirapikan.

Botol angin adalah sebuah tabung yang berfungsi untuk menampung udara bertekanan yang dihasilkan dari kompresor. Tabung ini harus memiliki kekuatan yang cukup untuk menampung tekanan udara maksimal dari alat peraga ini yaitu 1,0 bar. Dengan demikian penulis memilih pipa PVC maspion ukuran 4 inchi sebagai bahan pembuat tabungnya, dimana pipa ini dipotong ukuran panjang 30 $\mathrm{cm}$. 
Untuk pembuatan kompresor penulis menggunakan mini compressor yang biasa digunakan untuk memompa roda sepeda motor, dalam hal ini cassing dari kompresor dibongkar hingga diambil bagian electro motor, piston, batang piston, serta liner dari piston kompresor, dikarenakan alat peraga ini dibuat untuk media pembelajaran sehingga harus terlihat gerakan piston yang dihubungkan dengan electro motor melalui engkol yang berupa roda gigi dalam memompa angin menuju ke botol angin.

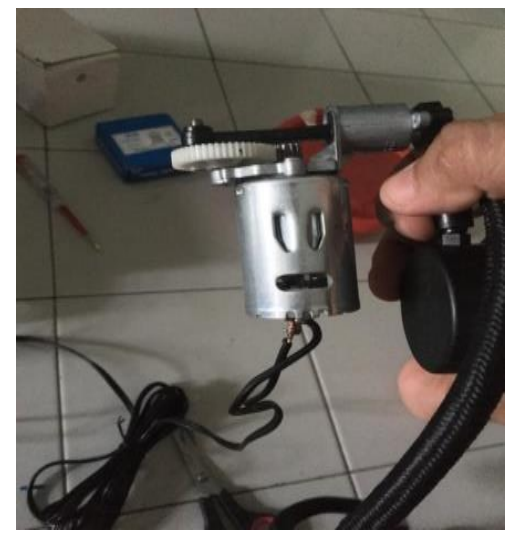

Gambar 5. electromotor, piston dan liner

Berikutnya adalah pemasangan manometer dan safety valve pada tabung udara. Manometer yang digunakan adalah manometer 1 bar atau 15 Psi, tekanan ini terbilang aman untuk tabung dengan bahan PVC. Untuk membuat lubang yang kedap setelah dipasang manometer dan safety valve maka dibuat packing dari bahan karet ban yang di perkuat dengan ring, kemudian dilem menggunakan lem besi atau defcon.

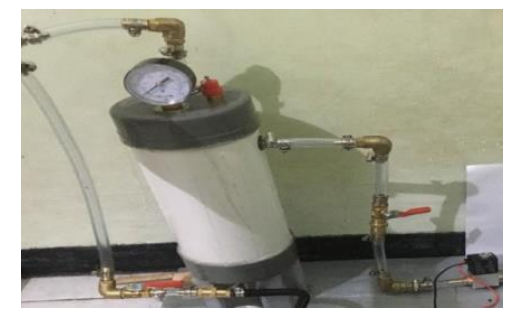

Gambar 6. Manometer dan safety valve pada tabung

Pada tabung, dibuatlah katup cerat untuk mengeluarkan angin dan embun di dalam tabung. Untuk lubang di katup cerat penghubung yang digunakan adalah napple ukuran 5/16" dengan ulir $1 / 4$ '.

Napple akan dihubungkan dengan selang angin kemudian dihubungkan dengan kran kuningan ukuran $1 / 4$ " karena ujung kran ini adalah napple ukuran $5 / 16$ sesuai dengan selang yang digunakan penulis. 


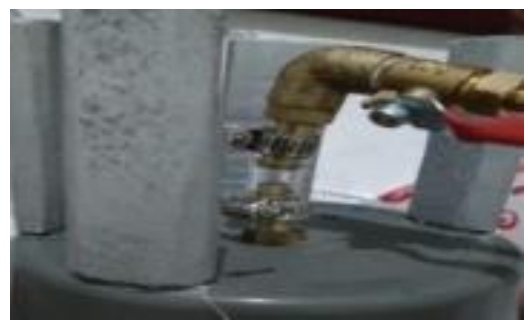

Gambar 7. Katup cerat (drain)

Untuk mengalirkan udara bertekanan pada sistem, penulis menggunakan selang udara transparan ukuran 5/16" adalah selang udara yang dipilih oleh penulis. Selang udara ini memiliki karakter transparan dan juga tebal, jadi selain kuat untuk dilewati udara bertekanan, selang ini juga enak dilihat karena warnanya yang transparan.

Selang yang penulis gunakan tidak semata-mata penulis langsung pasang, melainkan penulis hubungkan dengan napple ukuran 5/16" seperti tersebut diatas tadi. Selain itu untuk membelokan selang, penulis menggunakan elbow kuningan dengan ulir ukuran $1 / 4$, yang nantinya dihubungkan dengan napple yang telah dihubungkan dengan selang. Untuk mengencangkan selang dengan napple maka perlu adanya klem pengunci agar selang tidak lepas dari napple.

Kran yang digunakan penulis untuk kran inlet dan outlet adalah kran yang sama dengan kran yang digunakan untuk katup cerat yaitu kran ukuran $1 / 4$ " yang berbahan dasar kuningan.

Agar udara start dapat masuk ke silinder mesin induk pada alat peraga yang penulis buat, maka dibutuhkan sebuah valve yang bisa terbuka otomatis ketika kran dialiri listrik, valve tersebut adalah selenoid valve. Tipe selenoid yang digunakan adalah tipe EVI 7/9 dengan spesifikasi $12 \mathrm{~V}$ DC, 6,5W dan arus $540 \mathrm{~mA}$.

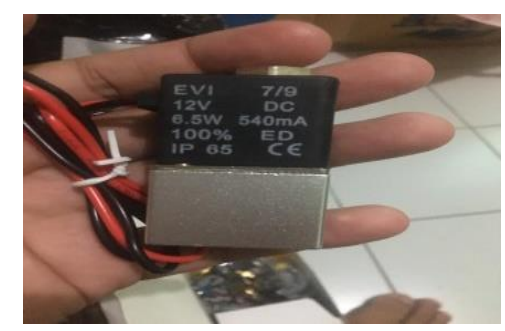

Gambar 8. Selenoid valve

Supaya pergerakan piston dari silinder mesin induk dapat terlihat saat distart, maka bahan yang digunakan untuk membuat liner haruslah bahan yang transparan, penulis menggunakan bahan botol yang memiliki profil permukaan silinder yang rata. Sama seperti halnya liner, crankcase pun harus dibuat dengan bahan transparan agar gerak dari crankshaft dapat terlihat. Bahan yang penulis gunakan untuk membuat crankcase ini adalah dengan menggunakan toples mika yang memiliki profil permukaan halus. Dimensi dari crankshaft adalah D $9 \mathrm{~cm}, \mathrm{P}$ $10 \mathrm{~cm}$, langkah berikutnya adalah melubangi bagian bawah toples untuk 
crankshaft. Dan bagian samping toples dibuat lubang sesuai diameter liner, karena akan disatukan dengan liner.

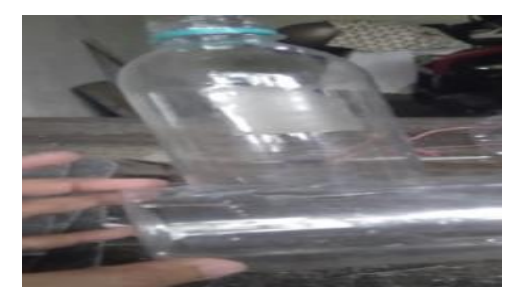

Gambar 9. Crankshaft

Untuk pembuatan crankshaft, bahan yang digunakan untuk membuat crankshaft adalah sebuah pipa bening berbahan hard plastic. Pipa memiliki dimensi ukuran diameter $10 \mathrm{~mm}$ yang kemudian dipotong sepanjang $3,5 \mathrm{~cm}$ berjumlah 2 buah.

Daun crankshaft pada alat peraga ini dibuat menggunakan bahan kayu sengon, bahan ini dipilih karena mudah dibentuk dengan cutter. Daun crankshaft yang penulis buat memiliki panjang $6,5 \mathrm{~cm}$, lebar $5,5 \mathrm{~cm}$ dan ketebalan $2,5 \mathrm{~cm}$. Pada daun crankshaft ini dibor dengan ukuran lubang $10 \mathrm{~mm}$ sesuai dengan crankshaft, dan dibor ukuran $8 \mathrm{~mm}$ untuk batang connecting rod.

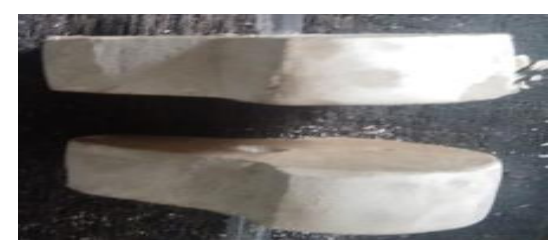

Gambar 10. crankshaft set

Batang torak dalam alat peraga ini dibuat dengan menggunakan bahan yang sama dengan bahan yang digunakan untuk membuat daun crankshaft.

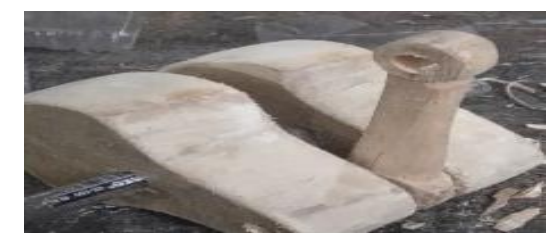

Gambar 11. batang torak

Penulis membuat piston dari bahan botol kimia ukuran diameter $6 \mathrm{~cm}$. Botol dipotong untuk diambil bagian bawahnya sepanjang $5 \mathrm{~cm}$. Kemudian botol diampelas ukuran 1000, agar nantinya cat menempel dengan baik. Penulis menggunakan cat silver. 


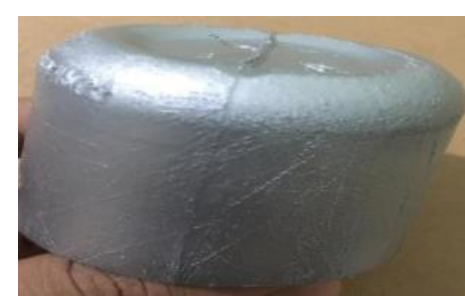

Gambar 12. Piston

Pada bagian roda gila atau flywheel, roda gigi yang digunakan memiliki spesifikasi:

Tabel 3. tabel ukuran roda gigi

\begin{tabular}{cc}
\hline Bagian & Ukuran \\
\hline Diameter luar & $50 \mathrm{~mm}$ \\
Diameter tengah bor & $10 \mathrm{~mm}$ \\
Tinggi gigi & $3 \mathrm{~mm}$ \\
Tebal & $7 \mathrm{~mm}$ \\
Jumlah gigi & 48 gigi \\
\hline
\end{tabular}

Untuk memasang roda gigi pada crankshaft agar kencang dan tidak lepas maka digunakan lem korea yang terkenal sangat keras.

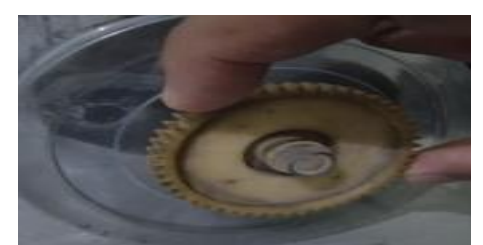

Gambar 13. Roda gila

Sumber penggerak yang digunakan penulis untuk menggerakan piston dan memutar crankshaft adalah sebuah dinamo motor DC. Dinamo DC ini memiliki tegangan $12 \mathrm{~V}$ dan arus 10A dengan ujung dinamo berupa pulley kecil. Agar posisi dari dinamo motor bisa sesuai dengan roda gila, maka dibuat dudukan dinamo motor dari bahan kayu.

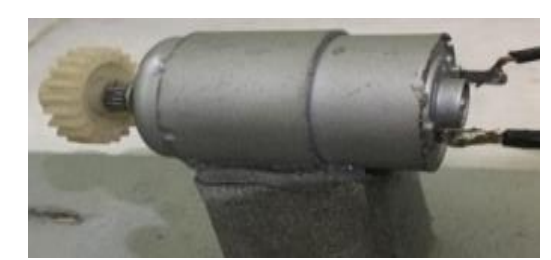

Gambar 14. Dinamo motor

\section{Pengadaan komponen Elektronika}

Daftar komponen elektronika yang digunakan penulis dalam sistem kontrol alat peraga ini terdapat pada tabel. 
Tabel 4. Daftar komponen elektronika

\begin{tabular}{ccc}
\hline Nama Komponen & Unit & Keterangan \\
\hline $\begin{array}{c}\text { Power supply } \\
\text { Module timer delay relay }\end{array}$ & 1 & $12 \mathrm{~V} 10 \mathrm{~A}$ \\
1 channel & 1 & Seri 3D4B \\
Module timer delay relay & 1 & Seri 4D3B \\
2 channel & 1 & B50K \\
Potensio & 1 & TIP 3055 \\
Transistor & 1 & Sakelar DC \\
Sakelar & 2 & \\
\hline
\end{tabular}

6. Pembuatan Skema

Sebagai perancang sekaligus penulis, maka tahap yang dilakukan setelah pengadaan alat adalah membuat skema rangkaian elektronika. Skema pembuatan rangkaian elektronika sistem kontrol ini penulis dapatkan dari berbagai riset di internet dan pengalaman penulis selama melaksanakan praktek laut diatas kapal, karena alat peraga yang dibuat penulis ini merupakan prototype mesin bantu.

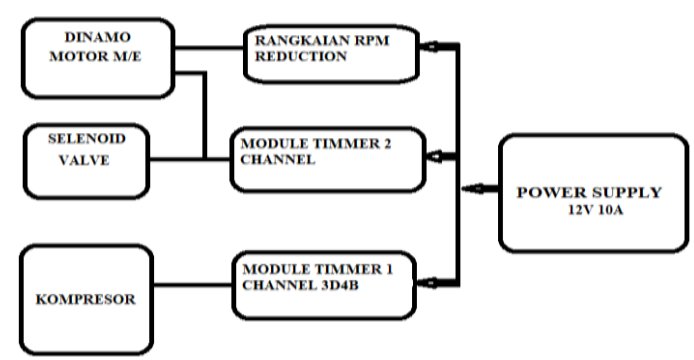

Gambar 14. Skema sistem kontrol

7. Perakitan

Dalam perakitan dan penghubung antar modul dan komponen, penulis menggunakan kabel sebagai medianya.

a. Power Supply

Power supply yang digunakan dalam penelitian ini adalah power supply 12V 10A. Dimana fungsi dari power supply adalah untuk mengubah tegangan AC menjadi DC. Power supply ini memiliki beberapa baut yang memiliki simbol antara lain Ground, L,N, V+, dan V- Untuk merangkai kable dari stop contact arus AC, maka diperlukan kabel dua buah. Kabel dari colokan masing masing dihubungkan dengan baut dengan simbol L dan $\mathrm{N}$.

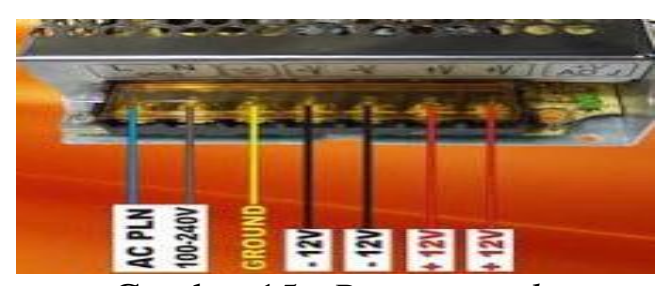

Gambar 15. Power supply 


\section{b. Modul timmer 1 channel 3D4B}

Modul timmer 1 channel $3 D 4 B$ adalah sebuah modul yang menggunakan sistem timmer delay relay (TDR) yang merupakan sebuah modul yang bisa diprogram dan berfungsi sebagai pengatur waktu suatu komponen listrik menyala, delay, atau mati. Untuk sumber listrik dari power supply di hubungkan dengan kabel melewati sakelar menuju ke input dengan kode 12V dan GND. Kemudian unruk kabel kutub positif dari dinamo kompresor dihubungkan ke baut penjepit dengan kode COM. Kemudian kita pasangkan lagi kabel dari modul kabel dipasang pada baut berkode No. kemudian disambungkan ke kutub V+ pada power supply. Untuk kabel negatif dari motor kompresor bisa dihubungkan langsung ke kutub V-power supply.Untuk rangkaian dapat dilihat pada gambar.

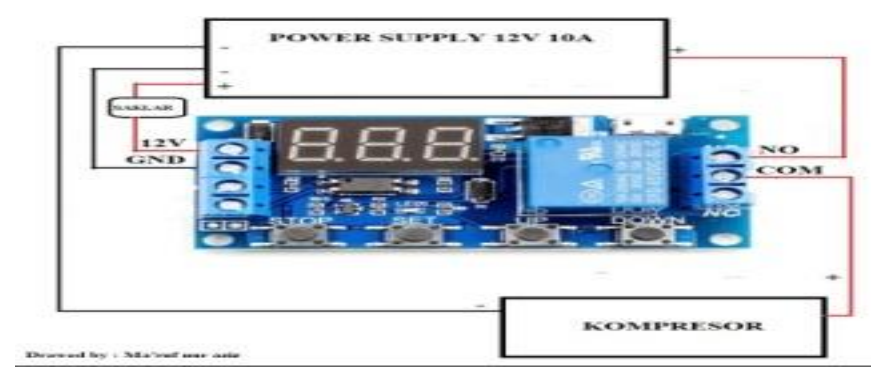

Gambar 16. Rangkaianwiring diagram modultimmer 1 channel

\section{c. Modul timmer 2 channel $4 D 3 B$}

Berbeda dengan Modul timmer 1 channel 3D4B, modul yang digunakan berikutnya adalah modul Modul timmer 2 channel $4 D 3 B$ yang memiliki perbedaan pada komponenya. Jika modul 1 channel itu hanya memiliki 1 buah relay di dalamnya, modul 2 channel ini memiliki 2 buah relay, sehingga modul ini dapat mengontrol 2 buah alat elektronik karena memiliki 2 output DC 12V sehingga modul ini yang penulis pilih.

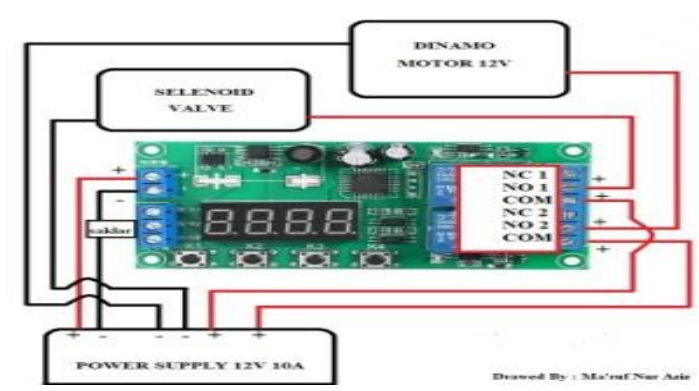

Gambar 17. Gambar wiring diagram modul timmer 2 channel 4D3B

Untuk merangkai kabel padamodul ini sebenarnya hampir sama dengan merangkai modul timmer 1 channel. Dimana pada modul ini kita menggunakan jalur NO bukan NC. Untuk merangkai modul, sumber listrik dari power supplypada baut L dan Ndi hubungkan dengan kabel melewati sakelar menuju ke input dengan kode $12 \mathrm{~V}$ dan GND. Kemudian unruk merangkai komponen 1 yaitu selenoid valvekabel positif dari selenoid valve disambungkan dengan baut penjepit dengan kode bertuliskan COM 1, selanjutnya kita sambungkan lagi kabel 
dari baut penjepit No. 1 ke power supply pada posisi V+.Sedangkan untuk kabel negatif dari selenoid valve langsung dihubungkan dengan kutub $\mathrm{V}$ - pada power supply.

d. Rangkaian potensio penurun RPM motor

Untuk menurunkan RPM dari dinamo motor ini, Komponen elektronik yang diperlukan adalah sebuah rangkaian sederhana yang terdiri dari kabel, potensio, dan sebuah transistor. Adapun potensio yang digunakan adalah potensio dengan tipe $\mathrm{B} 50 \mathrm{~K}$ atau bisa juga menggunakan potensio $\mathrm{B} 100 \mathrm{~K}$, disini potensio yang digunakan penulis adalah potensio tipe B50K yang merupakan potensio yang banyak dipasaran.

Sedangkan untuk transistor yang digunakan adalah transistor dengan kode TIP 3055 dan untuk menjaga agar transistor tidak cepat rusak karena overheat, perlu juga aluminium pendingin untuk transistor,arus yang mengalir melewati rangkaian potensio sederhana ini adalah arus 10A sehingga hal ini akan membuat transistor akan cepat panas jika beroperasi lama.

Transistor terdiri dari tiga kaki yaituBase,Collector, dan Emitoratau bisasa disingkat kaki B,C,dan E. Karena ini merupakan rangkaian sederhana, maka tidak diperlukan papan PCB untuk membuat rangkaian ini.

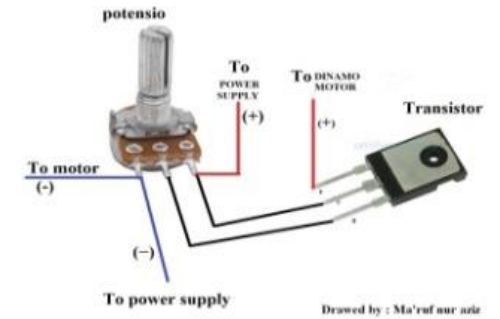

Gambar 18. Rangkaian sederhana potensio

8. Pemrograman sistem kontrol pada modul.

Setelah semua komponen serta modul telah dirakit, maka langkah berikutnya adalah memprgram modul yang penulis gunakan dalam rancang bangun alat peraga ini.

a. Memprogram modul timmer 1 channel 3D4B

Untuk memprogram modul jenis ini tidak memperlukan program dengan komputer atau yang biasa disebut coding, pemrograman modul jenis seperti ini dilakukan langsung pada modulnya dengan menekan button pada modul. Modul timmer 1 channel 3D4B memiliki 4 buah tombol (button) yaitu tombol Stop, Set, UP dan Down.

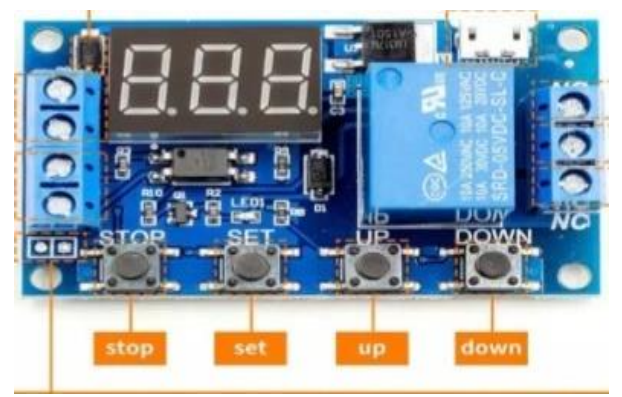

Gambar 19. Tombol program modul 
b. Memprogram modul timmer 2 channel 4D3B

Tabel 5. Tabel kode program

\begin{tabular}{cc}
\hline Kode program & Keterangan \\
\hline F-1 & T1 $O N>\mathrm{T} 2$ ON (non delay) \\
F-2 & T1 $O N>D E L A Y>\mathrm{T} 2$ ON \\
F-3 & $D E L A Y>\mathrm{T} 1$ ON> T2 ON \\
F-4 & T1 $O N>\mathrm{T} 2$ ON $>D E L A Y$ \\
F-5 & TI $O N>D E L A Y>\mathrm{T} 2$ ON $>D E L A Y$
\end{tabular}

Program yang digunakan untuk modul ini para alat peraga yang penulis buat adalah kode program F-1. Program ini dipilih karena program yang dibutuhkan adalah program waktu selenoidon (T1) kemudian dinamo motor penggerak piston (T2) on sehingga program F-1 adalah program yang tepat. Cara memprogramnya adalah dengan terlebih dahulu menyalakan modul, kemudian tekan tombol K1 dan tahan. Berikutnya tekan $\mathrm{K} 2$ untuk memilih program pilih program dengan kode F1, kemudian tekan tombol K3 untuk memilih setting waktu T1 atau T2. Untuk mengatur lama waktu komponen bekerja tekan K2 kemudian untuk menaikkan atau menurunnkan angka bisa gunakan tombol K3. Setting waktu yang digunakan untuk T1 pada alat peraga ini adalah 1 detik dan untuk T2 adalah 30 detik.

\section{Prinsip Kerja prototype main air compressor udara start mesin induk}

Rancang bangun alat peraga yang telah dibuat penulis setelah bangunan alat peraga serta elektronika dan sitem kontrolnya telah dipasang dan diprogram maka sistem kerjanya sudah dapat beroperasi sesuai dengan fungsi masing - masing bagian.

\section{Sistem kerja kompresor udara}

Kerja kompresor pada alat peraga ini adalah gerakan berputar dari dinamo motor kompresor yang menggerakan poros engkol sehingga piston bergerak naik turun, saat piston turun udara masuk melalui celah sempit dibawah liner kemudian piston naik celah tertutup dan udara didorong piston melalui klep non return kemudian diteruskan ke botol udara.

2. Udara di dalam tabung

Udara dari kompresor kemudian ditampung pada tabung udara hingga tekanan yang ditentukan yaitu 0,8 Bar. Sebelum memprogram modul timmer, terlebih dahulu dilakukan perhitungan waktu yang ditempuh kompresor hingga tekanan mencapai 0,8 bar setelah ditemukan waktu yang di tempuh yaitu 20 detik, barulah modul timmer kompresor diprogram untuk beroperasi selama 40 detik kemudian akan otomatis mati. Sehingga ketika angin pada tabung diisi hingga tekanan 0,8 bar kompresor akan otomatis mati.

\section{Starting mesin induk}

Sistem kerja selanjutnya dari udara bertekanan setelah mencapai tekanan 0,8 bar adalah proses start mesin induk. Tombol start mesin induk ditekan kemudian modul timmer 2 channel akan bekerja untuk membuka katup selenoid selama 1 detik sehingga udara dari dalam tabung akan masuk ke dalam silinder engine melalui selenoid yang terbuka kemudian dinamo motor penggerak crankshaft 
akan beroperasi dan selenoid tertutup. Piston akan bergerak naik turun karena digerakan oleh dinamo motor.

\section{Tujuan pembuatan alat peraga}

Setelah proses pembuatan alat peraga dari awal hingga ahir telah dilaksanakan alat peraga telah siap untuk digunakan dan memperoleh banyak manfaat dari dibuatnya. Untuk itu pembuatan alat peraga ini bertujuan:

1. Memberi manfaat pada penulis

Tujuan yang dicapai pertama adalah untuk memberi manfaat bagi penulis yang merancang dan membuat alat peraga ini. Penulis dapat mengerti bagaimana proses dari pembuatan alat peraga kompresor angin udara start di atas kapal dengan melakukan pembuatan alat peraga kompresor tersebut untuk media pembelajaran sehingga pemahaman dan wawasan dari main air compressor starting air main enginedapat lebih mudah dipahami. Selain itu Penulis dapat mengetahui bagaimana sistem kerja dari rancang bangun alat peraga main air compressor starting air system melalui peragaan dari alat peraga yang penulis buat.

2. Memberi manfaat bagi lembaga pendidikan

Dengan penelitian ini taruna yang akan melaksanakan praktek laut dapat menambah wawasan dasar tentang permesinan bantu di atas kapal, terutama salah satu permesinan bantu yang juga merupakan komponen penting dalam permesinan kapal yaitu main air compressor. Dengan Skripsi ini pembaca dapat mengetahui proses pembuatan alat peraga, dan juka sistem kerja dari main air compressor beserta komponen komponennya.

\section{PENUTUP}

\section{Kesimpulan}

Dari hasil penelitian yang telah dilakukan serta pembahasan yang telah diuraikan pada karya tulis skripsi ini, maka dapat ditarik kesimpulan sebagai berikut: Bahan dasar kayu, mika, dan kuningan merupakan bahan yang paling banyak digunakan pada pembuatan bagian dari alat peraga ini yang dikerjakan dengan menggunakan gergaji tangan, serta cutter sebagai pemotong bahan, ampelas sebagai penghalus bahan dan mesin bor tangan yang digunakan untuk melubangi. Perancangan elektronika pada alat peraga ini lebih simple karena menggunakan modul timmer delay relay sebagai komponen pengatur pada sistem alat peraga yang penulis buat, sehingga tidak memperlukan komponen micro controller dan arduino yang memperlukan pemrograman dari komputer. Tentu saja untuk program modul timmer yang ada tidak secanggih micro controller. Perancangan dan pembuatan alat peraga ini dapat bermanfaat bagi instansi, karena dapat digunakan sebagai media pendidikan tentang permesinan di atas kapal terutama kompresor udara start.

\section{DAFTAR PUSTAKA}

Annisah, S. (2017). Alat peraga pembelajaran matematika. Tarbawiyah: Jurnal Ilmiah Pendidikan, 11(01), 1-15. 
Arsyad, A. (2013). Media pembelajaran edisi revisi. Jakarta: Rajawali Pers, 24, 4.

Astriawati, N. (2020). Development of interactive media based on videoscribe with realistic mathematics education approach to navigation. Math Didactic: Jurnal Pendidikan Matematika, 6(3), 321-333.

Borg dan Gall. (2015). Pengenalan Metodologi Penelitian danpengembangan. danpengembanganRineka Cipta.

Fitrah, M. (2018). Metodologi penelitian: penelitian kualitatif, tindakan kelas \& studi kasus. CV Jejak (Jejak Publisher).

O’Brien, J. A. and G. M. M. (2010). Management System Information. Mc-Graw Hills.

Prasetyo, D. (2018). Evaluasi Hasil Belajar Menggambar Dan Mendesain Mesin Antara Taruna Dari Input Sma Dan Input Smk Dengan Metode KelompokKelompok Kecil Jurusan Tehnika Di Pip Semarang. Dinamika Bahari, 9(1), 2189-2196.

Saifuddin, M. S. I., \& Wekke, I. S. (2018). Strategi dan Teknik Penulisan Skripsi. Deepublish.

Tahara, H., \& Sularso, P. (2006). Kompresor: Pemilihan, Pemakaian, dan Pemeliharaan. Jakarta: PT. Pradnya Paramita.

Timotius, K. H. (2017). Pengantar Metodologi Penelitian: Pendekatan Manajemen Pengetahuan untuk Perkembangan Pengetahuan. Penerbit Andi. 